\title{
Teaching Pattern Research of Advanced Mathematics in the perspective of Micro Lecture
}

\author{
TANG Yugui ${ }^{1, a}$ \\ ${ }^{1}$ Nanchang Institute of Science and Technology, Nanchang 330108,China \\ atangyuguinc@126.com
}

Keywords: Micro lecture, Advanced mathematics, Teaching pattern, Micro lecture viedo

\begin{abstract}
The teaching effect of advanced mathematics i in colleges and universities has not been very expectable because of its complex and difficult characteristics and the influence of the exam-oriented education idea, students can't understand teachers' teaching. And with the application of information technology, especially the application of multimedia technology in teaching activity, new type of video teaching represented by micro lecture in colleges and universities has been more and more popular. This paper setting the concept of micro lecture as the breakthrough point discusses the improvement ideas in the teaching model and the optimization method of micro lecture based on the current situation and problems of micro lecture teaching mode expecting to provide certain reference for the quality of advanced mathematics teaching and improvement of students' mathematical learning ability.
\end{abstract}

\section{Concept of Micro lecture}

In the teaching of colleges and universities, advanced mathematics has always been the difficulty in the teaching because of the complexity and the high requirements for students' thinking ability, not easy to understand and master for the students. Affected by traditional examination-oriented education idea at the same time, teachers' teaching of the advanced mathematics also mostly stays in the classroom on the thinking of knowledge, neglecting the students' participation and independent thinking in learning activities which makes student unable thoroughly comprehend knowledge of the advanced mathematics and be harmful to exercise students' thinking ability and to the development of its mathematical creativity and overall quality[1]. Therefore, to explore a new effective advanced mathematics teaching mode is the hot spots for educators to research and exploration. The author applied the new bored type of teaching in the teaching area, micro lecture, into the teaching mode of advanced mathematics- a kind of new media teaching tactics aiming at independent project or system in curriculum structure- based on the application of multimedia technology in teaching in recent years and the demands for the modernization and informatization of education in the Planning Outline of Reform and Development in Medium and Long-term Education in Our Country (2010-2020) , and discusses the improvement and upgrading methods of the teaching mode and promotes the teaching measures and the optimization of the advanced mathematics[3].

The concept of micro lecture is first proposed and established by one minute scholar David Penrose in the United States, it is a brand new teaching method with the video to transmit the knowledge in accordance with the teaching goals and objectives and curriculum structure, to establish the knowledge teaching content through the design as a logical link project or unit series. It condensed the concepts, explanation and examples in a minute for the popularity of organic chemistry knowledge. Developed up to now, it mainly refers to small video as the carrier of teaching resources, with 15 to 20 minutes or even more short as the unit of the course, learners' autonomous learning in order to get the best effect, producers in advance the informatization instructional design meticulously, in the form of multimedia display, for a subject knowledge or the teaching steps and design and development of a new type of contextualized support a variety of ways of learning online video courses. Micro lecture can be used as the auxiliary teaching resources, formal learning can also act as informal learning autonomous learning resources, it has great 
prospects for development to cultivate students' study habits in autonomous learning, autonomous exploration, to achieve a targeted personalized learning so as to improve students' learning interest, arouse the learning demand. Micro lecture is based on information technology, especially the development of multimedia technology and the education resource integration needs and teaching mode. Compared with the traditional classroom education, the micro lecture is shorter and smaller on scale design with effective mutual combination of teaching resources, and decomposes the complex integration of the knowledge content to let students fully grasp of learning skills in the limited class hour. It involves variety of resources, including education, reflection, review and testing in diversity courses providing students with comprehensive project of classroom learning channels, promoting the development of the students consciousness and ability, thus it has been gradually adopted and popularized in the current college teaching[5].

Micro class basically has the following characteristics: (1) educational, micro class as short of online education resources can solve the problem of practical teaching.(2) Purpose, micro class has a clear teaching objective, teaching method, teaching content and teaching activities together to achieve the teaching goal in the shortest time but in the most effective way.(3) Interesting, micro lesson is interesting, is able to attract learners' enthusiasm, active learning rather than a boring.(4) $\mathrm{P}$ Participatory, micro class as a new type of learning resources adapts to the mobile learning, in learning and online learning, has a wide range of participatory, free application as far as possible, cancel the restriction of browsing.

\section{Teaching conditions and problems of advanced mathematics}

Restricted by unbalanced regional teaching resource allocation and the development, the current advanced mathematics exists a lot of congenital problems in the implementation and improvement of the teaching mode: 1) The students' quality is low. Along with the education expansion and the construction of colleges and universities, a number of colleges and universities recruit students under the pressure to reduce gradually the recruitment of students' scores, which lowers the quality of students, the teaching effect and quality of students making school difficult to ascend, without any significant number of high education achievement makes the best students to find more capable, and cause a vicious cycle. At the same time, students' poor quality also makes even recruit college matriculation eugenics, boost up whole teaching effect and the atmosphere. It will also affect the development of healthy birth. 2) To learn advanced mathematics is difficult. Different from other courses in colleges and universities, the number of high difficulty difficult for college students, learning and mastering the difficult is more, a lot of foundation weak students in study half-heartedly, difficult to understand spoken class. If the teacher does not pay attention to improve the learning method, can only continue to drag university eugenics and the gap between poor students, makes the advanced mathematics of teaching can't push the progress of most of the students mathematical ability. In addition to the above situation, the current teaching mode is one of the biggest worry is that teachers' teaching and the method of backward consciousness, students can rely on education make up the day after tomorrow, poor ability of advanced mathematics is difficult to choose the appropriate level of students teaching on learning. And the lack of teachers' teaching idea and way will affect the students understanding and progress of mathematical knowledge, concrete manifestation in: 1) some teachers hold the ideas for the cramming teaching, emphasize knowledge instilled in the number of higher education and the means of exams, students are subject to academic tasks and passive knowledge learning, no independent thinking and to explore the space of learning and motivation. Formed in the long term thinking, will only "do" not "problem solving", students' lack of knowledge and skills to understand, is test-prep tricks can not grasp the understand and apply mathematical knowledge in practical problems. Teachers in the classroom (2) the principal position of students also influences the interaction between teachers and students, students in a passive recipient roles, not included in the teaching activity space, cause and lack of communication between teachers and students is that much more into not into the teaching process, make its produce the advanced mathematics of learning interest and enthusiasm, cause the classroom learning atmosphere dull teaching quality is poor. 


\section{The necessity of bringing in micro lecture into advanced mathematics}

The development of Micro lecture has brought a profound change to school education as a kind of scenery change in a contextualized teaching link or point and it supports for multiple learning ways of new type of online video application of course in the higher mathematics classroom, the class subversion of the traditional teaching mode.

1. It will turn over the classroom to promote interaction between teachers and students. Advanced mathematics teacher must first threw down the traditional old teaching methods, make the topic of teaching lesson and knowledge through teaching design into an important teaching courseware before teaching, shot into small videos to show to students by changing some text narrative knowledge into images For example, it is very hard for a freshman to understand the concept of function limit to accept advanced mathematics. If teachers firstly analyze the concept of sequence limit through teaching courseware tend to be infinite sequence of an infinite number of points fall on neighborhood within the drawing process with dynamic images, static of knowledge will be dynamic images easy to understand for students. The three-dimensional knowledge on the plane, the student union very intuitive to understand the concept of sequence limit, secondly, again by the function definition is a function of the special series, thus a natural concept of the function limit are given. Such a complex concept can be solved easily through small micro class. Furthermore, due to short micro class generally in ten minutes, it also asks students to watch the video combining with teaching material carefully after class. The problem of micro class gathered together, theme outstanding, it can explain a knowledge or solve a problem in a very hort time. Students know that the purpose of the micro class when they see the title of the micro class. The advanced mathematics with more learning knowledge needs students to spend more time to digest the heavy and difficult knowledge through autonomous learning of micro class clearly seen at a glance, then deepen understanding through micro lesson video, which will be easy to find out the key point of this section.

2. Teachers change from teaching material passer into curriculum developers. With the introduction of micro lesson the teacher in class micro video in combined with the characteristics of the students' actual needs and the choice of teaching content and the arrangement of the order and grasping the key difficulty making appropriate adjustments according to the requirements of the follow-up professional courses complement some relevant knowledge of mathematics. Teachers in making micro class will study and reflect on the problems found in the process of teaching, and then the problem of research into class, which is both teaching and research process, and effectively promote teachers' business growth. Micro class is in the form of a novel variety, production process of micro lesson is a sharing of resources, the exchange process of accumulation, the teachers in the process of producing micro class will also learn some excellent micro lessons on the Internet video. For example, for the same micro course of knowledge points has different styles and analysis and interpretation of knowledge, teachers can learn advantages and complement from each other, improve their ability for the integration of teaching resources. It is also a process of learning and improving, which encourages teachers gradually to change from the material teacher into curriculum developers.

3. Solve the contradiction between teaching content and class due to the advanced mathematics of content more school each semester is limited, classroom teachers reflected in period cannot complete all the teaching content. And micro class as a new type of teaching resources to solve the contradiction between the teaching content and class, text, images and sounds, intuitive vivid show the learning content. The use of courseware combining with the concept from curved trapezoid area and variable speed linear motion ways of abstracting through the computer image intuitive showing the whole process of the formation of the concept. It also can display on the screen when the interval segmentation, the more fine small rectangular area of the approximate tune the trapezoid area so intuitive is concise and clear to introduce a very abstract complex concepts to students, greatly saves time. 


\section{The improvement and application of advanced mathematics in the view of micro lecture}

To explore the innovation and optimization methods of advanced mathematics teaching mode in micro perspective, the author combines with the characteristics of advanced mathematics of course teaching, improves ideas and measures with small class as a pattern, designs on a particular project for a mathematical knowledge and guides students to learn, think and explore independently through the video, and deepen the understanding of the theory of knowledge in the process. It can be divided into the following several aspects[2].

(1) Based on discipline: to build advanced mathematics curriculum on the basis of overall grasp of the teaching goal and task of advanced mathematics, refine and design based on course content of each unit and chapter, to design thematic structure covering knowledge point and difficult point problem of this section with rigorous logic relation between each course project, the project to connect each other, all constitute the whole teaching course system. The projects are in accordance with the structure of the interaction "ask questions - analysis problems - problem solving", and each has a logical step by step to promote relations, making each unit project to ask questions and solve for each other. To promote the progressive type of thematic teaching knowledge, reduce the students' learning and understanding the difficulty through the definition of a theorem to drive another demonstration of theorem, to facilitate this chapter one by one.

(2) Based on course unit: the design of the classes would show the advantages of small class in the teaching of the advanced mathematics of video, and the micro video class is the important way of the implementation. On design of video production, teachers should pay attention to the guide function leading question to stimulate students learning thinking on teaching content and knowledge learning through micro lesson video, and collect students' feedback at the same time, so as to improve and optimize the teaching deficiencies and defects in the design of the video content. Video design should be based on each unit, produce each special micro video independently for each unit to achieve a section lesson knowledge points corresponding to a micro video, making full use of teaching resources to improve classroom teaching results and efficiency. Teachers can use micro video through the geometry, the expression form of intuitive understanding of specific ways for the students to easy video image to complete the unit teaching to help students acquire the knowledge.

(3) To achieve interaction between teachers and students in class teaching. Teaching combined with micro lesson video broadcast is mainly divided into two ways: one is that a teacher let students observe micro video class in the classroom along with the teacher's explanation; the other one is to put micro lesson video onto the network learning platform for students' autonomous learning[4]. As in the interpretation of the limit theory, to deepen students understanding of the formula of learning, teachers can add the video with other instances in the field of contact to supplement the professor. Students change from passive recipients to the main body of learning activities, and teachers change from the knowledge spreader to the guider for students' autonomous learning. Students have to participate in the activities of learning enthusiasm and motivation, the lecturer can remove the heavy burden, focus on stimulating students' active learning and independent thinking direction. The relationship between teachers and students to become harmonious, good atmosphere of classroom teaching can help students to develop progress. At the same time, micro lecture teaching also gives students more thinking space, different from the traditional education for middle school students absorbing knowledge all the class, students have more independent time and opportunity for thinking and cognitive view video to carry out more on the analysis of the video content and key points of knowledge, review and inquiry activity, so that teaching and learning are powerful combined with each other in the course, the depth of the students' learning and initiative get greater development and promotion, finally promotes the teaching quality of advanced mathematics.

\section{Summary}

In the perspective of micro lecture, the author put forward several ideas and measures to the 
improvement and application of advanced mathematics teaching mode, expecting to promote beneficial suggestions to solve the plight of the current problems of higher education and its development. However, the advanced mathematics teaching is a difficult task that the students are easy to feel hard to understand and use in the learning process which affects the quality of education and the development of students' math quality. So, on the one hand, we should do further optimization in the curriculum design and teaching based on its feature advantages, at the same time, to guide students to learn actively and think independently as a direction to improve the teaching mode according to the specific problems of advanced mathematics knowledge and teaching and enhance the level of advanced mathematics teaching achievements and students learning ability. In order to adapt to the development of information era, and promote reform of higher mathematics teaching mode to a new type of teaching resources, the micro lecture. If they could apply the modern teaching method in a scientific and reasonable way, it will bring new vitality to the traditional higher mathematics teaching.

\section{References}

[1] C.Y. Tang. Inquiry research and teaching practice of the principle of automatic control course

[1]T.S.Hu. Connotation understanding and teaching design method of the micro lecture [J] Guangdong education, 2014 (4).

[2]Y.Q.Gao. The application of the formula of advanced mathematics in the t mathematics teaching [J]. Education and teaching research, 2013, (02): 68-70.

[3]L.Zhou, Y.L.Cheng, J.Zhang. The teaching reform of advanced mathematics under the background of higher education[J]. Theory of observation, 2015 (6) : 172-173).

[4] W.W.Tong. Several realizations of teaching of advanced mathematics [J]. Mathematics teaching research, 2014, (5) : 65-68.

[5] J.Zhou, L.Tian, W.Tian. Research on effectively improving the teaching quality of advanced mathematics[J]. Theoretical observations, 2015 (10) : 161-162).

[6]X.Z.Meng, R.M.Liu. The theory and practice of design of micro lecture[J]. Journal of distance education, 2014 (6) : 24-31. 